\title{
Whole Exome Sequencing
}

National Cancer Institute

\section{Source}

National Cancer Institute. Whole Exome Sequencing. NCI Thesaurus. Code C101295.

A procedure that can determine the DNA sequence for all of the exons in an individual. 